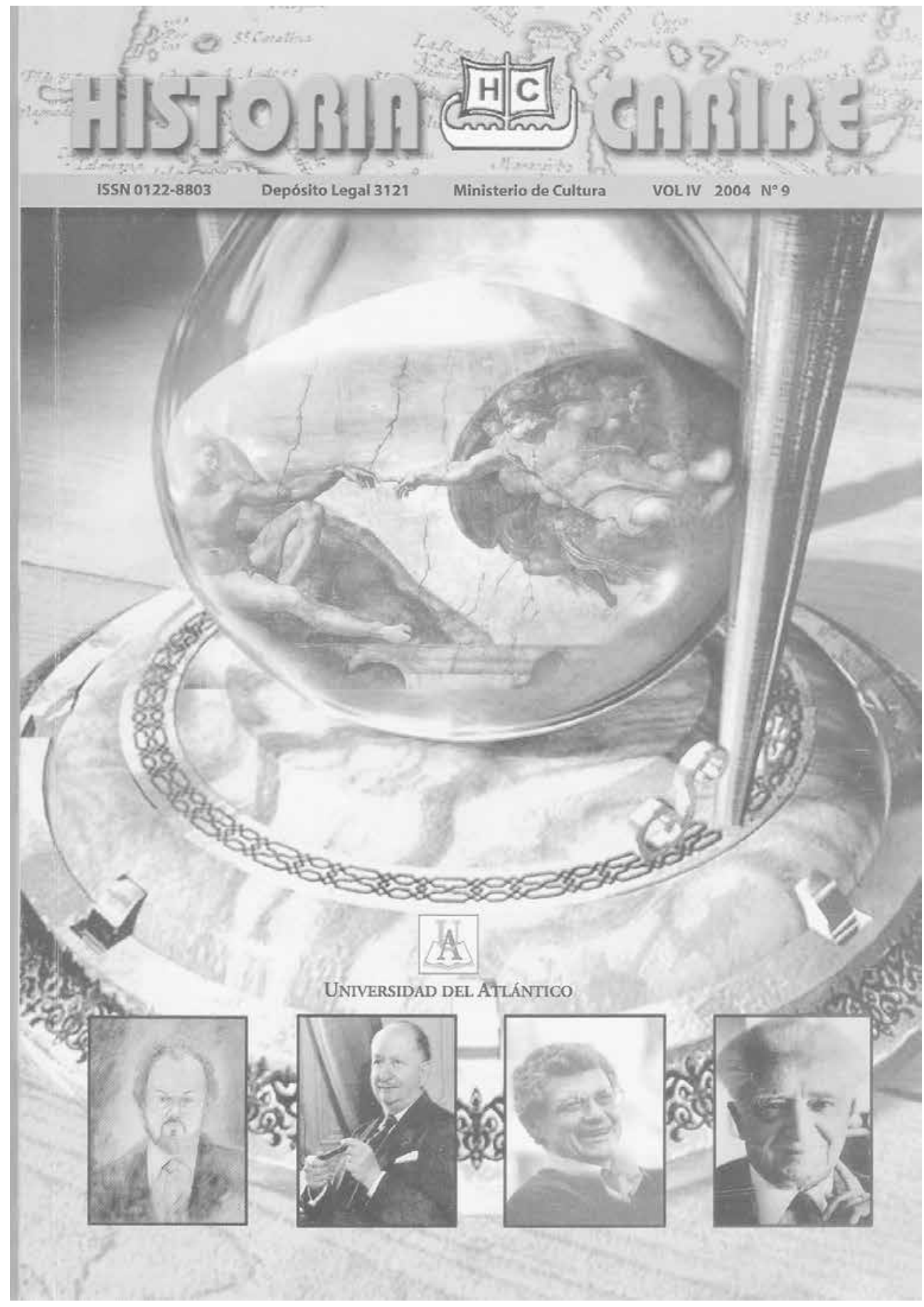




\title{
El papel de Colombia en la Segunda Guerra Mundial. Desde el inicio de la conflagración hasta el ataque japonés a Pearl Harbor*
}

\section{Andrés Felipe Mesa Valencia}

\begin{abstract}
Miembro del Grupo de Investigaciones Identidades e imaginarios polítcos de la Universidad Nacional de Colombia, sede Medellín (Colombia). Correo electrónico: afmesa@unal.edu.co. El autor es egresado de la Maestría en Historia de la Univesidad Nacional de Colombia, sede Medellín (Colombia). Entre sus líneas de investigación tenemos los temas de historia política de Colombia, política exterior colombiana e historia del siglo XX.
\end{abstract}

Recibido: 27 de marzo de 2014

Aprobado 30 de abril de 2014

Modificado: 12 de septiembre de 2014

Artículo de investigación e innovación

DOI: http://dx.doi.org/10.15648/hc.26.2015.10

Este artículo forma parte de la tesis de Maestría "La política exterior colombiana durante la Segunda Guerra Mundial", realizada para obtener el título de Magíster en Historia de la Universidad Nacional de Colombia, sede Medellín (Colombia).

Esta publicación está bajo una licencia Creative Commons Reconocimiento-Compartir Igual 3.0

\section{(cc) BY-SA}


El papel de Colombia en la Segunda Guerra Mundial. Desde el inicio de la conflagración hasta el ataque japonés a Pearl Harbor

\title{
Resumen
}

El presente artículo aborda el comportamiento exterior de Colombia durante la primera fase de la Segunda Guerra Mundial, es decir, desde septiembre de 1939 hasta diciembre de 1941. Detalla en qué medida las decisiones políticas de la nación respecto al conflicto, iban en concordancia con las de Estados Unidos. Sin embargo, hace hincapié en el liderazgo que llevó a cabo el gobierno de Eduardo Santos para salvaguardar la integridad de toda América. La neutralidad y el esfuerzo por congregar el consenso continental fueron, durante el periodo mencionado, aspectos fundamentales para la interacción internacional del país.

Palabras clave: Eduardo Santos, política exterior colombiana, Segunda Guerra Mundial, neutralidad, Panamericanismo, Estados Unidos.

The role of Colombia in the Second World War. Since the beginning of the conflagration until the Japanese attack on Pearl Harbor

\begin{abstract}
This article discusses the external behavior of Colombia during the first phase of the Second World War, that is, from september 1939 to december 1941. It details the extent to which the political decisions of the nation on the conflict, were in accordance with those of the United States. However, leadership emphasizes that held the government of Eduardo Santos to safeguard the integrity of all America. Neutrality and the effort to assemble the continental consensus were, during the period mentioned, fundamental aspects of the country's international interaction.
\end{abstract}

Key words: Eduardo Santos, Colombia's foreign policy, Second World War, neutrality, Pan-Americanism, United States.

O papel da Colômbia na Segunda Guerra Mundial. Desde o início da conflagração até que o ataque japonês a Pearl Harbor

\section{Resumo}

Este artigo discute o comportamento externo da Colômbia durante a primeira fase da Segunda Guerra Mundial, ou seja, a partir de setembro 1939 até dezembro de 1941. Ele 
detalha a medida em que as decisões políticas da nação sobre o conflito, estavam de acordo com o Estados Unidos. No entanto, enfatiza a liderança que assumiu o governo de Eduardo Santos de salvaguardar a integridade das Américas. Neutralidade e do esforço continental para reunir consenso foram, durante o período mencionado, a chave para a interação internacional no país.

Palavras-chave: Eduardo Santos, da Colômbia política externa, Segunda Guerra Mundial, neutralidade, americanismo, Estados Unidos.

\section{Le rôle de la Colombie dans la Seconde Guerre mondiale. Depuis le début de l'incendie jusqu'à ce que l'attaque japonaise sur Pearl Harbor}

\section{Résumé}

Cet article traite du comportement extérieur de la Colombie au cours de la première phase de la Seconde Guerre mondiale, qui est, à partir de Septembre 1939 à Décembre 1941. Il détaille la mesure dans laquelle les décisions politiques de la nation sur le conflit, étaient en conformité avec la États-Unis. Cependant, souligne le leadership que le gouvernement a entrepris d'Eduardo Santos pour préserver l'intégrité des Amériques. La neutralité et l'effort continental pour recueillir des consensus ont été, au cours de la période mentionnée, la clé de l'interaction internationale dans le pays.

Mots-clés: Eduardo Santos, politique étrangère de la Colombie, Seconde Guerre mondiale, neutralité, américanisme, États-Unis.

\section{INTRODUCCIÓN}

Solo habían transcurrido unas cuantas horas de la invasión a Polonia por parte de la Alemania nazi y ya el gobierno colombiano se aprestaba a definir la posición de la nación con respecto al conflicto que apenas comenzaba en el Viejo Mundo. El presidente Eduardo Santos, el primero de septiembre de 1939, se dirigió al Congreso a través de una alocución por radio. Su mensaje exponía claramente "la posición del gobierno y del pueblo colombianos ante la presente situación europea”.

En su discurso, Santos enfatizó sobre el cambio que se daría en la política internacional del país, aseguraba que sería de "una claridad diáfana y de 
una nitidez que corresponda a los principios y necesidades que la determinan”. Los fundamentos que guiarían el proceder de esa política serían: “el estrecho entendimiento con los países americanos" y "la unidad de acción para la defensa de la democracia y del continente". Actuar en el marco de la solidaridad americana era el interés primordial del gobierno Santos en el entendido de que así se mantendría la unidad del continente.

En este sentido, el presidente colombiano hizo también un llamamiento a los gobiernos de América ese mismo día. Su pedido iba en el sentido de congregar a las naciones americanas en el sentimiento de una consistente cohesión hemisférica para lograr así "la defensa de los bienes esenciales que nos son comunes: la plenitud de nuestra independencia y soberanía, la normalidad de nuestro desarrollo económico, la esencia de nuestros regímenes democráticos, la paz a cuya sombra fecunda quieren los pueblos de este hemisferio realizar sus destinos"".

Debido a este protagonismo que tuvo el gobierno colombiano para congregar a las naciones de América, el 4 de septiembre el embajador de Colombia ante los Estados Unidos, Miguel López Pumarejo, recibió una comunicación de La Sociedad para las Américas, en la cual se le informaba sobre el reconocimiento que la organización hizo al presidente Santos. En el mensaje se resaltaba el llamado de Santos a la cooperación sobre las bases de la Convención Panamericana ${ }^{2}$, para asegurar la neutralidad del hemisferio occidental con respecto a la guerra. La preocupación por proteger la independencia de cada nación era una constante en cada uno de los mandatarios americanos, pero solo podía ser posible en la medida en que América estuviese al margen de la conflagración europea ${ }^{3}$.

$1 \quad$ El Tiempo, Bogotá, 2 de septiembre, 1939, 1 y 17.

2 El Panamericanismo se consolidó a través de una serie de conferencias conocidas como Conferencias Panamericanas, en las cuales los dirigentes de las repúblicas americanas se reunían para definir lineamientos comunes a toda América, tales como la no intervención y la solución pacífica de los conflictos. Ver: César Torres del Río, “Colombia y su política exterior. 1938-1948” (tesis de Maestría en Historia, Facultad de Ciencias Humanas, Universidad Nacional de Colombia, 1990), 12-98.

3 Archivo General de la Nación. Ministerio de Relaciones Exteriores (AMRE), Legación de Colombia en Washington, transferencia 5, t. 1, caja 43, carpeta 287, f. 196. 
El presidente de La Sociedad para las Américas, D. Stockton Stevens, finalizaba su carta diciendo: "I sincerely hope that the Republic of Colombia will be successful in its leadership to keep the American Republics out of Old World Feuds". ("Sinceramente espero que la República de Colombia tendrá éxito en su liderazgo para mantener a las Repúblicas Americanas al margen de las disputas del Viejo Mundo"). De esta manera, la idea de una neutralidad duradera e inquebrantable se caracterizaba como el motor del Panamericanismo cuando estalló la Segunda Guerra Mundial.

Desde luego, la neutralidad hemisférica iba de la mano con la decisión política de los Estados Unidos. El embajador colombiano en Washington envió a la Secretaría General de la Presidencia de la República en Bogotá el 6 de septiembre, una nota en la que advertía sobre la postura estadounidense ante el inicio de la guerra: Estados Unidos había optado por declararse neutral ${ }^{5}$.

Ante la postura estadounidense es interesante detenerse en la opinión del columnista Américo Latino ${ }^{6}$, quien desde el diario conservador El Siglo comentó: "El gobierno de Washington según parece, ha cambiado de táctica y se mantiene ferviente defensor de la neutralidad de la Unión”. Esta actitud estadounidense no podía más que generar desconfianza en el resto de América, ya que Franklin D. Roosevelt podría, en cualquier momento, olvidarse de su propósito de no extinguir la paz de su país y de América, y enviar a los campos de batalla europeos la neutralidad continental. A modo de vaticinio, Américo Latino escribió: "Lo malo sería que [...] resolviera a última hora el presidente Roosevelt despachar toneladas de soldados en barcos de emergencia para que en columna cerrada se hicieran matar en Francia, presionando a Sur América para que rompa ridículamente su neutralidad"7. Este tipo de augurios eran propios de la línea de pensamiento del laureanismo, que se caracterizaba por su animadversión hacia los gobiernos norteamericanos en razón, tanto de la separación de Panamá,

4 AMRE, Legación de Colombia en Washington, transferencia 5, t. 1, caja 43, carpeta 287, f. 196.

5 AMRE, Legación de Colombia en Washington, transferencia 5, t. 1, caja 43, carpeta 287, f. 203.

6 Seudónimo del conservador Luis Alfredo Otero. Ver: David Bushnell, Eduardo Santos y la política del buen vecino (Bogotá: El Áncora Editores, 1984), 24.

$7 \quad$ El Siglo, Bogotá, 5 de septiembre, 1939, 8. 
como por representar, según Laureano Gómez, el espíritu protestante. Al respecto señala el historiador David Bushnell:

“[...] la desconfianza y la antipatía de Gómez hacia los Estados Unidos se derivaban en última instancia de lo que él creía era una diferencia insalvable entre los valores culturales de América Latina, por una parte, y América sajona, como a menudo la llamaba, por la otra. América sajona no sólo era protestante sino materialista de corazón; América Latina era católica y más sensible a las cosas del espíritu"8.

\section{La antesala de la Reunión de Cancilleres en Panamá}

El 4 de septiembre de 1939, Eduardo Santos dirigió al país un discurso en el que sustentó la posición neutral del gobierno colombiano:

"Ante el hecho, infinitamente deplorable y trágico, de la guerra europea, el gobierno con plena conciencia de su responsabilidad, quiere reiterar a todos los colombianos la seguridad que él tiene de que el país puede esperar con calma el desarrollo de los acontecimientos, porque su soberanía está garantizada, y su estructura económica es suficientemente fuerte para afrontar esta grave emergencia con todas las posibilidades de éxito. Esas posibilidades se aumentarán hasta convertirse en certeza si se evitan pánicos y nerviosidades exageradas que carecerían de toda justificación" 9

Ante el conflicto en Europa la sociedad colombiana debería estar tranquila, ya que tanto la soberanía como la economía de la nación permanecerían intactas y, en consecuencia, serían lo suficientemente sólidas para afrontar la situación de emergencia. Aunque no por esto la seguridad de la nación iba a dejarse en manos del azar: "El gobierno espera que el sentido de la responsabilidad y el celo por los intereses públicos de cuantos tienen el encargo de informar al país, bastará para asegurar los resultados que hoy son

8 David Bushnell, Eduardo Santos y la..., 40.

9 El Tiempo, Bogotá, 4 de septiembre, 1939, 7. 
indispensables y para no poner en peligro en forma ninguna, la seguridad de la nación", aseguraba el presidente que en esta materia se tomarían las medidas que fueran necesarias.

Además, Santos instaba a la opinión pública para que actuara con "exquisita prudencia" respecto a las diversas opiniones de los extranjeros -evidentemente eran los ciudadanos de los países beligerantes a los cuales se refería el mandatario- residentes en el país. Aunque el gobierno aseguró que exigiría de parte de estos "huéspedes de la república" plena sumisión a las leyes, no debe pasarse por alto que la neutralidad no implicaba, bajo ninguna circunstancia, entrar en enemistades innecesarias con los gobiernos del Eje, y principalmente con el Reich alemán ${ }^{10}$.

Un día después de declarar su neutralidad, el 5 de septiembre, el gobierno de Franklin Roosevelt persuadió a todos los gobiernos americanos para que acudieran a una reunión donde se darían cita todos los cancilleres del continente, con el fin de llegar a consensos con respecto al tema de la neutralidad americana.

El 6 de septiembre, el ministro de Relaciones Exteriores colombiano, Luis López de Mesa, dirigió una nota al embajador de Estados Unidos en Colombia, Spruille Braden, en la cual expresaba que el gobierno de Colombia había sido notificado por los de Gran Bretaña, Francia y Polonia con respecto al estado de guerra que existía entre estas naciones y Alemania. Así las cosas, mediante el Decreto 1776 del 6 de septiembre de 1939, nuestro país manifestó que "observará completa neutralidad en el actual conflicto europeo", notificando así al gobierno estadounidense su posición frente a la guerra ${ }^{11}$.

Este mismo día, Santos y López de Mesa enviaron a la embajada de Colombia en Estados Unidos una comunicación, con el fin de que se hiciera extensivo al gobierno estadounidense lo que significaba para Colombia la Reunión de Cancilleres proyectada en la ciudad de Panamá. En este sentido se expresó el gobierno colombiano:

10 El Tiempo, Bogotá, 4 de septiembre, 1939, 7.

11 AMRE, Diplomática y consular, transferencia 1, vol. 1, t. 710, f. 211. 
"[El] Gobierno considera que la importancia de la Conferencia de Panamá será quizá más grande en lo económico que en lo internacional. Creemos que en esa Conferencia se tomarán acuerdos para uniformar la manera como todos los países entiendan y practiquen las normas de la neutralidad y la manera de proceder en todos los casos con los países beligerantes y especialmente con los buques que puedan asilarse en nuestros puertos y con los interese de los extranjeros beligerantes en nuestras naciones"12.

Se consideraba que en esta Conferencia era necesario tomar decisiones que condujeran a "uniformar" la manera en que todas las repúblicas americanas debían entender y practicar las normas de la neutralidad, y esto aunado a un aspecto de fundamental importancia: ¿cómo se debería proceder con los países beligerantes? Si buques de esos países llegaran a asentarse en puertos americanos, se establecerían directrices sobre cómo deberían actuar los gobiernos americanos en pro de la defensa de la soberanía.

Por otra parte, con respecto a los intereses de los extranjeros de los países beligerantes en el continente, la Conferencia de Panamá debería establecer pautas acerca de las colonias extranjeras, y sobre cómo estas necesitaban amoldarse a la neutralidad, sin riesgo de que pudieran violarla.

Sin embargo, insistían el presidente y el canciller, en que lo más importante era estudiar las medidas económicas para defender a América de las "consecuencias de la guerra”, y todo esto bajo la consideración de mantener al continente comunicado, especialmente en materia de navegación, más aún, cuando las líneas de navegación europeas podrían traer perjuicios en el intercambio comercial tendiente a fortalecer la solidaridad económica del continente americano. Por esto, era necesario que asistieran a la Conferencia, además del ministro de Relaciones Exteriores, los ministros de Economía y Hacienda.

"[...] consideramos que lo más esencial de esa Conferencia será estudiar las medidas económicas que sirvan para defender a Amé-

12 AMRE, Legación de Colombia en Washington, transferencia 5, t. 1, caja 43, carpeta 287, ff. $204-205$. 
rica de las consecuencias de la guerra; para garantizar los servicios de comunicaciones en todos [los] sentidos, especialmente de navegación, compensando con mutua ayuda los perjuicios que pueda traer la suspensión de líneas de navegación europeas; la protección de los americanos residentes en países beligerantes y las facilidades del intercambio comercial que tiendan a fortalecer la solidaridad económica del Continente"13.

El interés primordial de Colombia estribaba en estar al tanto de los movimientos norteamericanos con respecto a política exterior. Al escribirle al embajador colombiano en Washington, el 6 de septiembre, López de Mesa le manifestaba la conveniencia que tendría para la nación su presencia (la del embajador) en Panamá, ya que así el gobierno colombiano sabría qué rumbos debería tomar.

Spruille Braden visitó al canciller López de Mesa para indagar sobre la posición colombiana respecto a la situación creada por la guerra. En nombre de su gobierno el embajador estadounidense le preguntó al ministro colombiano "Si Colombia quería asociarse al Gobierno de los Estados Unidos y a otros Gobiernos americanos para proponer conjuntamente una invitación a aplicar el procedimiento de consulta previsto, reuniendo una Conferencia interamericana en Panamá [con el] fin de cambiar ideas sobre las medidas tendientes a asegurar la paz en el Continente americano"14.

A lo cual el Ministro respondió afirmativamente. Braden expresó que igual insinuación se había hecho a los gobiernos de: Argentina, Brasil, Chile, Cuba, México, Panamá y Perú, y que se esperaba la confirmación de cada uno de ellos.

No obstante, el interés mostrado por los diferentes países para reunirse en Panamá era poco. El embajador de Colombia escribía al presidente Santos desde Washington el 13 de septiembre: “Aunque los colegas aquí en Washington son partidarios [de la] consulta no me pareció en reunión ayer que 
estuvieran entusiasmados con la conferencia lo cual atribuyo en parte a ignorancia general de lo que Estados Unidos van a proponer"15.

Además, el gobierno colombiano tenía sus dudas con respecto a la Argentina, pues de todas las repúblicas americanas era la que más reacia se mostraba a alinearse según las directrices norteamericanas. "Sigue pareciéndonos oscura [la] actitud [de] ciertos países, especialmente Argentina”, manifestaba el presidente Santos al embajador en Washington. "Díganos", continuaba el presidente, "si existe allá el temor de que actitud [de] algunos países suramericanos pudiera debilitar manifestaciones solidaridad de Buenos Aires y Lima, cosa que nos parecería muy grave para futuro político continental"16.

A pesar de todo esto, las relaciones entre Colombia y Alemania en términos políticos y económicos siguieron funcionando de manera normal. Prueba de ello es que tan solo a unos pocos días del comienzo de la guerra, el 12 de septiembre, el gobierno de Colombia recibió la visita “del antiguo Ministro de Finanzas del Reich y Presidente del Reichsbank, ilustre personalidad y una de las más altas autoridades mundiales en materias económicas"17. Solo después, con la entrada en contienda de los Estados Unidos la situación cambiaría.

Desde el diario El Siglo, se criticaba el proyecto de una Reunión de Cancilleres en Panamá. Según Américo Latino, la neutralidad y la solidaridad debían ser dos "postulados inatacables" en toda América, mientras el con-

15 AMRE, Legación de Colombia en Washington, transferencia 5, t. 1, caja 43, carpeta 287, f. 183.

16 AMRE, Legación de Colombia en Washington, transferencia 5, t. 1, caja 43, carpeta 287, f. 190. En la evolución del Sistema Panamericano se llevaron a cabo, desde finales del siglo XIX, una serie de ocho conferencias en las diversas ciudades capitales de América para consolidar la unión panamericana. Las últimas dos habían sido llevadas a cabo en Buenos Aires y Lima. La primera conocida como la Séptima Conferencia Panamericana o Conferencia de Consolidación de la Paz, celebrada en 1936, en la cual se proponía, ante el evidente fracaso de la Sociedad de Naciones para prevenir conflictos y garantizar la paz, que la Unión Panamericana debía ejercer funciones claramente políticas para garantizar la unidad y la paz de América. Y la segunda, la Octava Conferencia Panamericana, del 9 al 27 de diciembre de 1938, en esta el interés de Colombia se concentraba principalmente en el fortalecimiento de una Liga Americana de Naciones, que garantizara la solidaridad americana.

17 AMRE, Legación de Colombia en Washington, transferencia 5, t. 1, caja 43, carpeta 287, f. 297. 
flicto no tocara "a nuestras puertas por parte de los beligerantes del viejo mundo”. Para garantizar la independencia y la integridad, Suramérica estaba interesada primordialmente en respetar la inviolabilidad de esos principios. Los contactos diplomáticos eran, según el periodista conservador, la mejor manera de preservar y mantener "esta salvadora política". Pero tales contactos solo se deberían llevar a cabo a través del "cable y la radiotelegrafía moderna”, pues serían más discretos y seguros que realizarlos públicamente en una conferencia internacional.

Se pensaba que en estas "pomposas reuniones" casi siempre se expresaba lo que no convenía hacer público; las cosas no resultarían como se tenía planeado debido a que se enardecían los ánimos, lo que se traducía en rivalidades que no permitían tomar oportunamente ninguna decisión definitiva: "llega el tiempo de obrar y las naciones interesadas están más distanciadas que antes de la reunión". La opinión del diario conservador era consecuencia de lo acaecido en la Conferencia Panamericana de Lima, en 1938, donde la resolución de la solidaridad continental, por haber sido definida a último momento y sin un análisis exhaustivo por parte de los asistentes, fue aprobada a pesar de su vaguedad y falta de solidez.

Según la opinión conservadora de El Siglo, la Conferencia de Panamá se convertiría en una estrategia de los Estados Unidos para persuadir a los estados americanos de romper su neutralidad. Esto, para Colombia en particular, podría traer consecuencias nefastas para su soberanía nacional. "Lo importante es que en Sur América no se nos haga perder forzosamente la neutralidad so capa de solidaridad"18.

Mientras se concretaban los últimos detalles para la Primera Reunión de Cancilleres, la situación en Europa empeoraba -concretamente en Polonia-, y la representación de Colombia ante ese país debía salir lo más rápido posible, según directrices del Ministerio de Relaciones Exteriores en Bogotá. El 21 de septiembre, el canciller López de Mesa, escribió al ministro legatario de Colombia en Londres, para que este informara a la 
Legación de Colombia en Varsovia que el gobierno colombiano había negociado con los alemanes la salida de Polonia de los diplomáticos colombianos. La evacuación se realizó sin inconvenientes, ya que las autoridades militares nazis de Varsovia habían sido informadas por el Gobierno del Reich, para permitir la salida de los colombianos ${ }^{19}$.

Según el embajador estadounidense en Colombia, los temas a analizar en la Conferencia de Panamá estarían contenidos en tres grandes tópicos de discusión: neutralidad, protección de la paz en el hemisferio occidental y cooperación económica.

Con respecto a la neutralidad, se debería hacer un estudio detallado de los deberes y derechos de los países neutrales y de los beligerantes, pues esta postura política garantizaría para el continente entero la conservación de la soberanía integral de cada nación y la paz. Al respecto estaba disponible una serie de medidas que debían tomarse: 1) evitar, a toda costa, violaciones de neutralidad y "actividades subversivas por parte de los nacionales de los países beligerantes" en territorio americano; 2) "hacer cumplir con las obligaciones de los beligerantes, de los barcos mercantes y de la aviación en las aguas y zonas territoriales neutrales"; 3) defender el desarrollo y auge del comercio internacional americano en altamar, tierra y aire; y 4) "cumplir con las obligaciones de neutralidad respecto de los países beligerantes".

En cuanto al mantenimiento de la paz hemisférica, el examen que debía llevarse a cabo en Panamá tendría que tener en cuenta las medidas necesarias para conservar a América al margen del conflicto que, eventualmente, pudiese penetrar el territorio por medio del aire, del agua o por tierra. Las aguas territoriales dentro de la zona de defensa habrían de ser custodiadas efectivamente para no tener hechos que lamentar en materia de beligerancia. Y por último, la cooperación económica debería ser analizada a través de la lente de la defensa, pues reforzando esta, se podrían garantizar medidas efectivas para la estabilidad financiera y económica de las repúblicas americanas $^{20}$.

19 AMRE, Diplomática y consular, transferencia 1, vol. 1, t. 710, f. 417.

20 AMRE, Legación de Colombia en Washington, transferencia 5, t. 1, caja 44, carpeta 295, f. 97. 


\section{Los proyectos y las decisiones de la Primera Reunión de CANCILleres}

Esteban Jaramillo, miembro de la delegación de Colombia en la Conferencia de Cancilleres de Panamá, que se llevó a cabo entre el 21 de septiembre y el 3 de octubre de 1939, expresó que todos "los representantes de las repúblicas americanas han acudido solícitos a esta reunión de consulta”. En palabras del representante colombiano esta respuesta de las naciones americanas significaba "decirle al mundo que las democracias de este continente están unidas por una inquebrantable decisión y un sincero espíritu de solidaridad". Esta acción conjunta convergía en la cooperación necesaria para hacerle frente a una eventual crisis económica desencadenada por los extraños peligros a que se veían enfrentadas todas las naciones del hemisferio ${ }^{21}$.

El único deseo para las 21 repúblicas americanas ${ }^{22}$-incluida Estados Unidos- iba en la vía de lograr hacer de América el baluarte de la democracia, "el último refugio de la civilización", mediante la paz y la prosperidad que se esperaba, pudieran ser los pilares fundamentales de las resoluciones de la Conferencia.

En este orden de ideas, se aprobó la creación de un comité consultivo económico. Dicho organismo debía convertirse en un elemento de "consulta, información y sugestión” en los problemas más apremiantes en cuanto al comercio, las finanzas y la economía de las naciones del Continente. Para el delegado de Colombia, esa creación era fundamental ya que sin ella "gran parte de nuestra labor quedaría trunca, o como en el vacío, por falta de un organismo que siguiera trabajando para la realización de varios objetivos contemplados en los proyectos sometidos a nuestro estudio". Sumado a esto, el programa económico adoptado debería tener un alcance considerable a fin de posibilitar un intercambio comercial estable y diná-

21 El Tiempo, Bogotá, $1^{\circ}$ de octubre, 1939, 1 y 10.

22 Los 21 estados miembros de la Unión Panamericana eran: Argentina, Bolivia, Brasil, Colombia, Costa Rica, Cuba, Chile, Ecuador, El Salvador, Estados Unidos, Guatemala, Haití, Honduras, México, Nicaragua, Panamá, Paraguay, Perú, República Dominicana, Uruguay y Venezuela. 
mico a pesar de las repercusiones económicas que el conflicto pudiera ocasionar en el continente americano ${ }^{23}$.

En el marco de este nuevo comité económico, sorprendió positivamente la decisión de las seis repúblicas centroamericanas -Guatemala, El Salvador, Honduras, Nicaragua, Costa Rica y Panamá-, que consistía en la conformación de un bloque centroamericano, que propendía a su "unidad espiritual", y esta unidad estaba completamente ligada a la cooperación de estos países para mantener la neutralidad y para guardar sus intereses comerciales mutuos, entendidos estos como el esfuerzo para buscar nuevos $\operatorname{mercados}^{24}$.

Con respecto al retraso en dar por terminada la Conferencia, el delegado colombiano explicaba que, aparte de la obligación de los delegados de las diferentes naciones de asistir a un nutrido itinerario de agasajos sociales, la razón fundamental era "el punto de vista que muchos miembros de la conferencia tienen sobre la actual situación internacional”, pues, al complicarse día tras día la situación europea ${ }^{25}$, se hacía aconsejable cierta demora con el fin de evitar una actuación precipitada con respecto al futuro del continente ${ }^{26}$.

El lunes 2 de octubre, la Conferencia consultiva de Panamá aprobó la Declaración de Panamá. En ella se establecía una zona de seguridad en torno a todo el continente americano. A las naciones beligerantes se les prohibió adelantar hostilidades en dicha zona, garantizando así que los barcos de carga o de pasajeros de cualquier nacionalidad que recorrieran las rutas interamericanas no estuvieran en peligro. Según la Declaración, el mar Caribe y el golfo de México se convertirían en mares internos con el fin de evitar los peligros de la guerra ${ }^{27}$.

23 El Tiempo, Bogotá, $1^{\circ}$ de octubre, 1939, 1 y 10.

24 El Tiempo, Bogotá, $1^{\circ}$ de octubre, 1939, 1 y 10.

25 Los acontecimientos europeos que preocupaban a los asistentes a la Conferencia de Cancilleres eran, entre otros: La mayor intervención de la Unión Soviética en la política europea; el viaje del ministro de relaciones exteriores italiano, conde Ciano, a Berlín, con lo cual Italia podría entrar en la guerra.

26 El Tiempo, Bogotá, $1^{\circ}$ de octubre, 1939, 1 y 10.

27 El Tiempo, Bogotá, 3 de octubre, 1939, 1 y 19. 
Tal como lo había propuesto el subsecretario de Estado estadounidense, Sumner Welles, recién había comenzado la Conferencia, el 26 de septiembre, los límites de la zona de seguridad se establecieron en 600 millas $^{28}$. Con respecto a la vigilancia permanente de esta zona, cada una de las naciones se comprometió a ejercer una custodia permanente en las costas de su propio territorio nacional, patrullando con la capacidad y los recursos de su propia flota, y llegando, eventualmente, a acuerdos bilaterales y multilaterales para un patrullaje conjunto. Así, cada gobierno debía "notificar" a las naciones beligerantes las demarcaciones de la mencionada área. Actuación esta, que contenía explícitamente la declaración de las repúblicas de América de que cualquier "acto de beligerancia dentro del cordón de seguridad constituye una amenaza contra la paz y seguridad de las naciones americanas".

Se trataba, pues, de configurar un "Mar Continental" donde las naciones signatarias debían intervenir para defenderlo. $\mathrm{Al}$ respecto se refirió el delegado del Brasil, Martin Pereira Souza, quien consideró que el principio del "Mar Continental", establecido en la resolución de la zona de seguridad, "no daña la soberanía de ninguna nación", puesto que la soberanía de cada república estaba fundamentada en las bases inviolables de la consulta (la no intervención, la conciliación y el arbitraje, y la vocación pacifista de los pueblos americanos). Así, “es en los océanos - continuaba Pereira Souzaque nos rodean donde está la suerte futura de nuestras soberanías, porque la protección de las tierras americanas será imposible como en el pasado sino con la seguridad de sus mares".

28 La zona de seguridad quedó meticulosamente establecida: "Partiendo del punto de la frontera entre los Estados Unidos y Canadá en la bahía de Passamaquoddy, a 44 grados 46 minutos, 36 segundos de latitud norte, y 66 grados 54 minutos segundos de longitud oeste; de allí directamente por el paralelo 44-46 y 36, hasta un punto situado a 60 grados al oeste de Greewich; de allí directamente hacia el sur hasta un punto situado a 20 grados latitud norte; de allí por la línea loxodrómica hasta un punto situado a 5 grados norte y 24 grados oeste; de allí directamente al sur hasta los 20 grados de latitud sur; de allí por la línea loxodrómica hasta los 58 grados de latitud sur y 57 grados oeste; de allí directamente hacia el oeste hasta los 80 grados oeste de longitud; de allí por la línea loxodrómica hasta un punto en el Ecuador en el grado 97 de longitud oeste; desde "ahia vía” la línea loxodrómica hasta un punto situado en los 15 grados de latitud norte y 120 grados de longitud oeste; desde ahí por la línea loxodrómica hasta el punto situado en los 48 grados, 29 minutos 38 segundos de latitud norte, y 136 grados de longitud oeste; y desde ahí directamente al este hasta la terminación en el Pacífico frente a la frontera entre los Estados Unidos y el Canadá, en el estrecho de Juan de Fuca". Ver: El Tiempo, Bogotá, 3 de octubre, 1939, 1 y 19. 
La Conferencia de Panamá fue la ocasión propicia para que los delegados suscribieran "una declaración común de neutralidad", formulando un común acuerdo en lo concerniente a la conducta de las naciones del continente "respecto a sus derechos, responsabilidades y obligaciones hacia los beligerantes". La neutralidad ya había sido esbozada como proyecto individual por parte de cada gobierno, sin embargo, como proyecto común del hemisferio apenas se concretaba en esta reunión ${ }^{29}$.

En general, los delegados presentes en la Conferencia interpretaron la declaración de neutralidad como una "extensa e importante doctrina" que daría lugar a "una importante influencia en la historia" de las Américas. La tendencia era considerar que la Buena Vecindad de Roosevelt -derivada a su vez de la Doctrina Monroe- por fin sería sustituida por el nuevo protagonismo de Centro y Suramérica ${ }^{30}$.

Una vez terminada se la consideró como "una de las más importantes Conferencias Panamericanas que haya habido", así lo estimó Luis López de Mesa después del satisfactorio balance de la reunión. Según el ministro de Relaciones Exteriores, prueba de ello era la gravedad del momento histórico, los temas que la habían motivado y la actitud de las delegaciones de los diferentes países.

La impresión primordial que la Asamblea dejó fue la "madurez conceptual del Continente". Esto se debía a que cada una de las representaciones de los países tenía lo suficientemente definido su derrotero con respecto a su correspondiente nación y al bien común de América. Solidaridad, paz, neutralidad y cooperación económica fueron los pilares fundamentales de las discusiones y las plenarias, para finalmente llegar a resoluciones de aceptación conjunta.

29 El Tiempo, Bogotá, 3 de octubre, 1939, 1 y 19.

30 Respecto a la política exterior estadounidense hacia el resto de América, hay que considerar varias etapas: $1^{\circ}$. La Doctrina Monroe, con la cual, desde la tercera década del siglo XIX, Estados Unidos prohibía a Europa interferir en América en beneficio de una intervención exclusivamente norteamericana; $2^{\circ}$. El Gran Garrote, ideado por Theodore Roosevelt para legitimar la intervención militar en el continente con el objetivo de neutralizar el "mal proceder crónico" de las repúblicas americanas; $3^{\circ}$. El Buen Vecino, política implementada por Franklin Roosevelt con el objetivo de mantener relaciones más cordiales y menos hostiles con los gobiernos americanos, mediante la modificación del comportamiento exterior de Estados Unidos. 
Para López de Mesa, la actitud unánime de un continente "sin una voz de discordancia" se explicaba por la preocupación de todos los mandatarios americanos por mantener el destino ideal para el hemisferio; que estaría marcado por los cuatro factores que fueron los mayores logros de la Conferencia de Panamá: solidaridad, que iría en el sentido de una cooperación interamericana que permitiera a cada nación defender efectivamente sus derechos nacionales. Paz, fundamental para la estabilidad hemisférica y porque con ella "se obtiene y perdura el ambiente moral de una cultura y de una civilización propicias al bienestar material y espiritual del hombre americano del presente y de futuras generaciones". Neutralidad, absolutamente necesaria para crear el aislamiento del "ciclón bélico que desuela al continente de la máxima cultura”, y la cooperación económica, uno de los grandes logros de la Conferencia, con la que se propendía por la equidad jurídica "que armonice, encauce y fecunde la riqueza y el trabajo del Hemisferio Occidental". Para entender el impacto de este acontecimiento en la opinión del ministro, basta citar sus palabras textuales: "Es un cuerpo inmenso de operaciones de porvenir y de leyes en gestación que proyectan en abanico, como un haz de luz, la obra de esta Conferencia, haciéndola germen de inconmensurables nuevas orientaciones jurídicas" ${ }^{31}$.

\section{Aplicación de la NeUtralidad}

El primero de noviembre de 1939, en Washington, se reunió el Consejo Directivo de la Unión Panamericana ${ }^{32}$ para aprobar el informe de una comisión especial, a la que se había encargado para establecer todo lo que correspondiera a la integración del Comité de Neutralidad que se constituyó en la Resolución de Panamá. Este informe sugería que se conformara el Comité de Neutralidad con los seis países miembros del Comité de Expertos para la Codificación del Derecho Internacional: Argentina, Brasil, Chile, Costa Rica, Estados Unidos y México. Y a estos debía agregarse un séptimo miembro, que podría ser escogido como sede del Comité de Neutralidad. Como la sede resultó ser Brasil, el Consejo debió elegir a un miembro adicional a los países ya representados. Se eligió a Venezuela

31 AMRE, Legación de Colombia en Washington, transferencia 5, t. 1, caja 44, carpeta 294, ff. 22-23.

32 Estaba conformado por un integrante de cada una de las repúblicas americanas adscritas a las Conferencias Panamericanas y a la Reunión de Cancilleres de Panamá. 
como el otro país miembro debido a su iniciativa en Panamá para la conformación del Comité de Neutralidad. Ante este evento, Colombia apoyó sin inconvenientes la designación de la nación vecina. Asimismo, todos los países miembros de la Unión Panamericana aprobaron la decisión ${ }^{33}$.

El 4 de noviembre de 1939, el Congreso de Estados Unidos aprobó el texto final de la resolución conjunta de neutralidad: "Public Resolution No. 54-76th Congress". Este documento, sancionado de inmediato por Franklin D. Roosevelt, sería conocido en adelante como Neutrality Act of 1939, y acogía la voluntad de los Estados Unidos de establecer los puntos claves contenidos en la nueva Ley de Neutralidad-que debía a su vez, servir de parámetro para el resto de América- referentes a salvaguardar su soberanía nacional, esto es, "la declaración de un Estado de guerra en Europa -sin peligro de que este repercutiera en América-, la definición de áreas de combate, el uso de los puertos y aguas territoriales de Estados Unidos, y colecta de fondos para países beligerantes -aquellos que eran aliados norteamericanos-". Es de notar que Estados Unidos, a pesar de su declaración de neutralidad, estaba, mediante esta Ley, poniendo de manifiesto ante América y Europa, los intereses norteamericanos que debían abstenerse de desestabilizar los poderes del Eje.

Era el gobierno estadounidense el que tomaba la decisión de definir cuándo existía un estado de guerra entre otros países. Y definido tal estado, se prohibía a los barcos americanos transportar materiales, artículos o pasajeros a los países beligerantes, a menos que el título de propiedad fuera traspasado a otro gobierno, corporación o particular ajeno a Estados Unidos. Se prohibía viajar en navíos beligerantes a los ciudadanos estadounidenses, y el porte de la bandera nacional norteamericana por parte de embarcaciones de países en guerra ${ }^{34}$ Disposiciones estas, que posibilitaban el liderazgo estadounidense en cuanto a la defensa y control del territorio americano, pues aunque fueron pensadas para los Estados Unidos, luego todas las repúblicas americanas deberían acogerse a ellas.

El 15 de diciembre de 1939, el canciller Luis López de Mesa escribió una

33 AMRE, Legación de Colombia en Washington, transferencia 5, t. 1, caja 43, carpeta 289, ff. 95-96.

34 AMRE, Legación de Colombia en Washington, transferencia 5, t. 1, caja 44, carpeta 293, ff. 18-21. 
comunicación al embajador de Colombia en Washington, en esta se refería a la Ley de Neutralidad de 1939, y a las disposiciones del gobierno de los Estados Unidos con respecto a ella. Uno de los aspectos fundamentales de la ley era la modificación de la cláusula cash and carry. En la tradicional doctrina de neutralidad estadounidense, esta cláusula permitía cierta flexibilidad en cuanto a que posibilitaba a los ciudadanos estadounidenses la venta de productos -no bélicos-a los países beligerantes. La cláusula, a partir de su innovación en los principios generales de la neutralidad, había alcanzado a abarcar, para finales de 1939, disposiciones sobre la venta de materiales de guerra. Aspecto que hubiera sido inconcebible en las anteriores leyes de neutralidad.

Según el informe de López de Mesa, las disposiciones correspondientes a la prohibición de los ciudadanos estadounidenses de viajar en barcos de países beligerantes, y a la cláusula cash and carry, daban como resultado una revolución en el pensamiento jurídico que primaba en las normas de neutralidad, según el cual "la neutralidad correspondía a los Estados pero, en ninguna forma, a los particulares como tales". El canciller recordaba cómo Colombia se había inspirado en las anteriores leyes de neutralidad estadounidenses: en la Primera Guerra Mundial, es decir, durante el tiempo que duró esta, el gobierno prohibió a los particulares (ciudadanos colombianos) todo el comercio de material bélico con los países beligerantes. Y para ese momento (diciembre de 1939), la intención primordial era hacer saber al gobierno norteamericano que el colombiano había "reproducido" unas prohibiciones idénticas a las del Neutrality Act of 1939, mediante el Decreto sobre reglas de neutralidad colombiana ${ }^{35}$.

\section{La Habana, el llamado a repensar el problema de la Seguri- DAD HEMISFÉRICA}

La cita que tuvo lugar en La Habana, entre el 21 y el 30 de julio de 1940, fue de crucial importancia para unificar posturas respecto a la política continental en caso de que el conflicto del viejo mundo adquiriera las dimensiones de una guerra mundial. Durante la sesión de apertura el presidente

35 AMRE, Legación de Colombia en Washington, transferencia 5, t. 1, caja 43, carpeta 292, ff. 21-22. 
cubano, Federico Laredo Brú, pronunció el discurso inaugural de la conferencia. En él se refirió, principalmente, a la integridad americana y al esfuerzo que debían asumir los gobiernos para preservarla. "Los peligros -sostenía Laredo Brú-, lo sabéis bien, aumentan cada día; afortunada sería nuestra América si, gracias a su aislamiento, puede continuar evitando las profundas reacciones consiguientes a los deplorables acontecimientos que presenciamos"36.

Las discusiones y los debates durante la estancia de los ministros de relaciones exteriores en Cuba giraron en torno a las situaciones más apremiantes para el continente. En primer lugar, todo lo referente a las colonias europeas en América, tema que había prendido las alarmas en Washington desde la arremetida de Hitler contra el occidente de Europa. Y por otra parte, el comportamiento militar que debía adoptar el continente frente a los actos hostiles en la zona de seguridad, que se lograría consolidando un sistema de asistencia recíproca y el establecimiento de bases militares que posibilitaran una cooperación defensiva.

Las fuerzas alemanas habían propiciado la rápida y contundente caída de Francia, y probablemente, Gran Bretaña no tardaría en caer también. Para Washington esto significó una de las principales dificultades para América, ya que esas naciones poseían colonias en el continente americano, y estas pasarían a ser dominios nazis. Por esto, el asunto de la transferencia de las colonias se convirtió en un tema de primer orden en la agenda de la Conferencia de La Habana ${ }^{37}$. Roosevelt ya había hecho saber al mundo que Estados Unidos no permitiría que Alemania se apoderara de las colonias francesas u holandesas en América. El mandatario norteamericano sostenía que "semejante cuestión cae dentro de la órbita de la Doctrina de Monroe en esta forma: los Estados Unidos no se apoderarán de ninguna de las posesiones insulares de las naciones conquistadas pero cree que el acto de disponer de esos territorios debería ser resuelta por todas las naciones americanas" 38 .

36 El Tiempo, Bogotá, 22 de julio, 1940, 1 y 6.

37 César Torres del Río, "Colombia y su...", 173-179.

38 El Tiempo, Bogotá, 7 de julio, 1940, 1 y 19. 
El 23 de julio la delegación de los Estados Unidos presentó a las demás naciones un proyecto en el que esbozaba la urgencia de implantar mandatos en las posesiones coloniales europeas. Lo cual solo podía ser posible en el marco de una política común, que se tenía que traducir en la posición unánime de no aceptar el traspaso de posesiones coloniales europeas en el hemisferio occidental "de una potencia no americana a otra no americana”. De este modo, se aprobaron una serie de medidas que imposibilitaban a Alemania tomar posesión de territorios americanos. Se reafirmó, como postulado fundamental para la paz e independencia hemisféricas, "el no reconocimiento y la no aceptación de la adquisición de territorio en este hemisferio por medio de la fuerza" 39 .

Sin embargo, para que todas las repúblicas americanas estuvieran de acuerdo con la nueva política de administración de las colonias europeas, debió quedar consignado en el papel que: "la posición legal de esas regiones geográficas es asunto de común interés para las repúblicas americanas, ninguna de ellas tomará acción, o iniciará o considerará propuesta alguna con respecto a ellas, sin previa consulta con las otras repúblicas americanas". Con esta cláusula las delegaciones tuvieron mayores inquietudes sobre posibles intenciones norteamericanas de aprovecharse de la situación ${ }^{40}$, pues quedaba claro que, en teoría, todas las repúblicas podían actuar como administradoras de las posesiones europeas.

También quedó constancia en el Acta de La Habana sobre administración provisional de colonias y posesiones europeas en América que en cuanto el conflicto terminara, y en tanto ya no existiera peligro alguno para América, las repúblicas de este continente retornarían las posesiones a sus "originales soberanos", siempre y cuando estos se hubieran liberado del yugo alemán y estuvieran en condiciones de "acometer la tarea de gobierno propio"41.

39 El Tiempo, Bogotá, 24 de julio, 1940, 1 y 15.

40 No obstante, Leopoldo Melo, jefe de la delegación argentina, se opuso, en principio, a las determinaciones con respecto a las colonias, pues según su opinión cualquier cambio debía reflejar "la libre voluntad de los pueblos afectados”. Ver: El Tiempo, Bogotá, 26 de julio, 1940, 1 y 6.

41 El Tiempo, Bogotá, 24 de julio, 1940, 1 y 15. 
Otro aspecto de crucial importancia tratado en la reunión de cancilleres fue el concerniente a la defensa americana. En el discurso pronunciado por el canciller López de Mesa el 27 de julio ante las demás delegaciones, este se refirió a la actitud de defensa que asumiría el gobierno colombiano. Señaló que ante una situación de conflagración mundial y de que el peligro asediara al Canal de Panamá, su gobierno no sería, bajo ninguna circunstancia, indiferente, pues este resultaba "indispensable para el bienestar y la prosperidad de Colombia y toda América del Sur, como puede serlo para la seguridad militar de los Estados Unidos". Aunque dejó en claro que, atendiendo al "anhelo de mantener en lo posible cierta neutralidad", no acudiría Colombia directamente a defender la zona del canal, no obstante, aseguraba que desde tierras colombianas a nadie se le permitiría amenazar la zona del istmo.

Para defender a América era necesario tomar decisiones con respecto a las violaciones de la neutralidad por parte de países beligerantes. En diciembre de 1939, se produjo un enfrentamiento, cerca de la costa noreste de Uruguay, entre navíos de guerra de Gran Bretaña y el acorazado alemán Admiral Graf Spee. Hechos como este ponían en riesgo el mar continental, y por ende, la firme posición de no intervención en el conflicto. Esto causó la protesta de las 21 repúblicas americanas, que el 29 de diciembre enviaron a los gobiernos beligerantes de Europa una nota en la que exigían "que impidieran a los barcos beligerantes abastecerse y reparar averías en puertos americanos" si estas embarcaciones habían puesto en vilo, mediante actos de beligerancia en la zona de seguridad establecida en la Conferencia de Panamá ${ }^{42}$.

La preocupación manifestada en Cuba por los gobiernos americanos se sustentaba, fundamentalmente, en que actos como el anterior no se fueran a replicar con más frecuencia debido al nuevo rumbo de la guerra. Así, la Resolución de Actos hostiles en las aguas territoriales y en la zona de seguridad fue el resultado de concienzudos análisis por parte de los representantes americanos que condenaban todo acto que fuera en contra de las soberanías nacionales y de la neutralidad hemisférica.

42 César Torres del Río, “Colombia y su...”, 180-184. 
Y en este mismo sentido, se elaboró un documento clave para garantizar la defensa de América: la resolución XV sobre "Asistencia Recíproca y Cooperación Defensiva". En esta se establecía que si un Estado no americano atentaba contra la inviolabilidad del territorio o la independencia política de un Estado americano, ese acto sería considerado como un acto de agresión contra todos los Estados firmantes de la declaración, lo cual implicaba que todos se unirían para tomar las medidas necesarias contra el agresor ${ }^{43}$. La cooperación defensiva y la asistencia entre las naciones americanas se convirtieron en los pilares que posibilitarían la proyección del continente como un todo contra la beligerancia externa.

Una vez finalizada la reunión de cancilleres, el secretario de Estado estadounidense, Cordell Hull, presentó un balance bastante alentador sobre las decisiones tomadas. Haber llegado a acuerdos sobre los peligros comunes, les permitió a los gobiernos americanos crear mecanismos para la "acción común", lo cual demostraba al mundo entero "la determinación inalterable de preservar y robustecer el espíritu del sistema continental de unidad y solidaridad". Desde luego, Hull hizo referencias a las divergencias, con respecto a las posesiones europeas, que al comienzo de la reunión se habían presentado pero que después de largas y sesudas discusiones, las naciones con posturas disidentes decidieron someter sus discordancias a la lucha por la paz y el orden del hemisferio.

Finalmente, la conferencia dejó como resultado el Acta de La Habana y la convención adjunta a ella, que daba a cualquiera de las naciones americanas el derecho de proceder, ya fuera aislada o conjuntamente, si alguna situación de emergencia lo ameritase, "de cualquier manera requerida para su propia defensa o la defensa del continente. Se esperaba que las medidas adoptadas en La Habana pudieran salir del papel y materializarse en las necesidades que más urgían al continente, para, de esta manera, diferenciarse de la muy teórica y poco práctica conferencia en Panamá. Cordell Hull finalizó su balance de La Habana, insistiendo en que ponerse de acuerdo para "combatir los efectos de la guerra" fue el logro más admirable de los cancilleres:

43 El Tiempo, Bogotá, 28 de julio, 1940, 1 y 19. 
"Como consecuencia de ella [la Conferencia de la Habana], las 21 repúblicas americanas convinieron en una política destinada a impedir que las posesiones europeas en América caigan en manos de otras potencias, a hacer del hemisferio una entidad que pueda bastarse a sí misma económicamente, y a ejercer funciones de potencia en ambos continentes, a fin de hacer perdurar su soberanía" 4 .

\section{1941, EL AÑo EN QUE AMÉRICA RESQUEBRAJA SU NEUTRALIDAD}

A comienzos del año 1941 el gobierno colombiano tendía a pensar que los últimos acontecimientos relacionados con la amenaza a la seguridad estadounidense y continental, debido al asedio nazi sobre Gran Bretaña, no podrían traer como resultado otra cosa más que la inminente participación estadounidense en la guerra. Además, en enero el Japón había reafirmado sus lazos de alianza militar con Alemania e Italia, según comunicaciones de la legación colombiana en Japón al ministro López de Mesa ${ }^{45}$. Factores, todos estos, que determinarían el nuevo rumbo que el continente americano, y en especial Colombia, debía seguir.

El canciller colombiano estuvo muy al tanto de los movimientos del gobierno estadounidense, mediante el intercambio de correspondencia con el embajador Gabriel Turbay. En misiva enviada por este a aquel, el 26 de marzo, informaba acerca de la "actividad cada día más intensa y definida desplegada por los Estados Unidos en materia de política internacional”, motivada por el "extraño y dudoso giro" que habían tomado últimamente los acontecimientos mundiales. López de Mesa le respondió al embajador solicitándole que estuviera al tanto de cualquier decisión de ese país, pues era fundamental para el gobierno nacional "seguir con atención los complejos aspectos de la lucha entre ideologías, sistemas de Gobierno, y predominio", que se conjugaban en el conflicto europeo, que cada vez iba tomando el cariz de mundial.

Las informaciones del embajador dejaban entrever que la neutralidad estadounidense podría, en cualquier momento, finalizar debido a "situaciones

44 El Tiempo, Bogotá, 31 de julio, 1940, 1 y 16.

45 AMRE, Diplomática y consular, transferencia 1, vol. 1, t. 722, f. 93. 
de sorpresa muy posibles" por parte del "bloque tripartita ítalo-germano-japonés". Señalaban, según el Ministerio de Relaciones Exteriores de Colombia, "con sobrada abundancia la gravedad [e] inminencia de acontecimientos que quizás inclinen en uno u otro sentido esa funesta balanza creada por la civilización para decidir entre fuerza bruta, el dominio y la ambición y la libertad, cultura y progreso de los pueblos" 46 .

El 27 de mayo, el presidente Roosevelt declaró el estado de emergencia nacional ilimitada - diferenciándolo del estado de emergencia limitada que se había proclamado desde el 8 de septiembre de 1939 para actuar dentro de los límites de los "tiempos de paz"- en todo el territorio de los Estados Unidos: "No aceptaremos un mundo dominado por Hitler", declaró el mandatario en el discurso que fue radiodifundido a todo el mundo. La nación norteamericana no podía "vacilar en la adopción de medida alguna necesaria para mantener nuestra libertad americana".

Para Roosevelt, entre los objetivos que los países beligerantes del Eje se proponían estaba el de acabar con el orden democrático para dominar a todos los pueblos, por lo que su nación tenía que dejar a un lado la indiferencia y "hacer frente de modo instantáneo y decisivo a todo intento de circundación hostil a este hemisferio... así como también para repeler la amenaza de incursión depredatoria por parte de agentes extranjeros". Aprovechó la ocasión para hacer un llamamiento a la unidad de las repúblicas americanas por la causa de la libertad "a lo ancho del mundo", ya que solo con un trabajo mancomunado podría mantenerse la independencia hemisférica.

Es interesante detenerse en el discurso de Franklin Roosevelt, ya que a partir de este se sentarían las bases del proceder futuro de los Estados Unidos. Para el presidente los problemas que convocaban al continente eran militares y aseveraba que "no podemos acercarnos a ellos desde el punto de vista de quienes piensan conforme a sus deseos o de los sentimentalistas. Lo que miramos son hechos fríos y duros". De lo que todo el mundo

46 AMRE, Diplomática y consular, transferencia 1, vol. 1, t. 723, f. 288. 
debía percatarse era que el conflicto que había empezado como europeo, había tomado las dimensiones de una guerra mundial, como el nazismo lo había planeado desde el principio: "Es evidente de modo inequívoco para todos nosotros, que si no se detiene a la fuerza el avance del hitlerismo ahora, el hemisferio occidental estará dentro del radio de las armas nazis de destrucción". Y para combatir esta amenaza el gobierno estadounidense se había encargado, después de la Conferencia de La Habana, de sancionar una serie de tratados de cooperación y asistencia con la mayoría de las naciones americanas: "Esto ha solidificado más nuestro hemisferio contra el peligro común”47.

El llamado a las naciones americanas era claro, debían actuar en concordancia con los Estados Unidos de América, pues estos se encargarían de proveer todo el material bélico para repeler la amenaza externa. Roosevelt trataba de mostrar cuál sería el panorama americano en caso de una invasión por parte de Alemania: "Asegurarían su dominio económico sobre nuestras varias naciones. Se encontrarían Quislings $\mathrm{s}^{48}$ para subvertir los gobiernos de nuestras repúblicas; y los nazis respaldarían sus quintas columnas $^{49}$ con la invasión, si eso es necesario" 50 . Y evitar el cometido de Hitler era el objetivo principal y la consecuencia máxima de los acuerdos de Panamá y La Habana. El compromiso que habían adquirido todos los miembros del Panamericanismo tenía que ser llevado a la realidad mediante la acción conjunta.

47 El Tiempo, Bogotá, 28 de mayo, 1941, 1, 9 y 16.

48 Hacía referencia al peligro que podría presentarse si políticos americanos decidieran aliarse con los nazis, tal como había ocurrido con el nazi noruego Vidkun Quisling, quien el 9 de abril de 1940, tras la invasión de Alemania a Noruega, tomó el poder mediante un golpe de Estado apoyado por los nazis. Según lo afirma Eric Hobsbawm, el término quisling se inventó para describir a las fuerzas políticas de los países atacados por Hitler que, "por convicción más que por interés", decidieron unir fuerzas al enemigo de su nación. Ver: Eric Hobsbawm, Historia del siglo XX (Barcelona: Ed. Crítica, 2001), 150.

49 Los quinta-columnas eran quislings. "El término mismo "quinta columna", tuvo origen en la Guerra Civil Española. Se le atribuye al general Emilio Mola, jefe de los "Nacionales", juntamente con Francisco Franco. Marchaba con cuatro columnas sobre Madrid y se refería a una "quinta columna", que estaba infiltrada entre los republicanos. Posteriormente se le dio a este término el significado de “infiltrados” o traidores". Ver: Enrique Biermann Stolle, Distantes y distintos. Los emigrantes alemanes en Colombia, 1939-1945 (Bogotá: Universidad Nacional de Colombia, División de Investigación Bogotá (DIB), Facultad de Ciencias Humanas, 2001), 180.

$50 \quad$ El Tiempo, Bogotá, 28 de mayo, 1941, 1, 9 y 16. 


\section{ConClusión}

Siguiendo los lineamientos estadounidenses, en noviembre de 1941 Colombia había retirado sus agentes y funcionarios consulares de todas las zonas europeas ocupadas por Alemania, sin embargo, en Berlín aún había representación diplomática nacional. $\mathrm{Al}$ respecto, el 24 de noviembre, escribió el canciller López de Mesa al adjunto de la Legación de Colombia en Alemania, Enrique Cucalón. En la comunicación se le encomendaba la tarea al ministro legatario, de encargarse de las necesidades que pudieran presentarse en aquellas zonas en lo relativo a "los derechos de los nacionales colombianos, envío de informes, a la realización de determinadas diligencias, etc.”. Así, la cancillería decidió nombrarlo encargado de los asuntos consulares en las zonas ocupadas por Alemania; el plan colombiano consistía en "conservar con aquellas zonas por lo menos un elemento de comunicación y de contacto puramente personal" 51 .

De este modo, se puede afirmar que, a pesar de la línea adoptada por Estados Unidos con respecto al conflicto y a la amenaza que significaba Alemania para el continente, el gobierno colombiano optó por no generar altercados de índole política con el gobierno del Tercer Reich que indispusieran las relaciones entre los dos países, es decir, mientras los Estados Unidos no se declarasen beligerantes, lo cual conllevaría inmediatamente a la aplicación de las disposiciones de la asistencia recíproca acordada en $\mathrm{La}$ Habana, Colombia no tenía motivos para descomponer sus relaciones con Alemania. Sin embargo esa situación no se sostendría por mucho tiempo.

Finalmente, la situación que hasta las postrimerías de 1941 había permanecido estable para América, esto es, la neutralidad -teniendo en cuenta que para mediados de 1941 la neutralidad estadounidense ya tomaba el cariz de beligerancia-, llegó a su fin. La amenaza creciente que significaba el Eje, representada principalmente en Alemania y Japón, se convirtió finalmente en el detonante de lo que sería la participación estadounidense -y americana- en la conflagración. Además, desde el 22 de junio la participación

51 AMRE, Diplomática y consular, transferencia 1, vol. 1, t. 730, f. 313. 
soviética en la guerra había cambiado de orientación: debido a la invasión alemana las huestes de Stalin lucharían del lado de las democracias contra el hitlerismo ${ }^{52}$. De esta forma, las condiciones estaban dadas para abordar el conflicto desde otra perspectiva, y Colombia estaba lista para asumir su papel de Buen Vecino.

\section{Bibliografía}

\section{Fuentes primarias}

\section{Archivo}

Archivo General de la Nación. Ministerio de Relaciones Exteriores (AMRE), Bogotá-Colombia. Diplomática y consular.

Archivo General de la Nación. Ministerio de Relaciones Exteriores (AMRE), Bogotá-Colombia. Legación de Colombia en Washington.

\section{Publicaciones periódicas}

El Siglo, Bogotá, 5 de septiembre, 1939.

El Siglo, Bogotá, 8 de septiembre, 1939.

El Tiempo, Bogotá, 2 de septiembre, 1939.

El Tiempo, Bogotá, 4 de septiembre, 1939.

El Tiempo, Bogotá, $1^{\circ}$ de octubre, 1939.

El Tiempo, Bogotá, 3 de octubre, 1939.

El Tiempo, Bogotá, 7 de julio, 1940.

El Tiempo, Bogotá, 22 de julio, 1940.

El Tiempo, Bogotá, 24 de julio, 1940.

El Tiempo, Bogotá, 26 de julio, 1940.

El Tiempo, Bogotá, 28 de julio, 1940.

El Tiempo, Bogotá, 31 de julio, 1940.

El Tiempo, Bogotá, 28 de mayo, 1941.

52 Desde ese momento la guerra ya no era tan claramente percibida como un "conflicto de las democracias contra los regímenes de partido único", debido a que la Unión Soviética se alió con el occidente democrático. Ver: David Thomson, Historia mundial de 1914 a 1968 (México: Ed. Fondo de Cultura Económica, 2006), 185. 


\section{Fuentes secundarias}

Arciniegas, Germán. "Eduardo Santos". En Nueva Historia de Colombia: Historia Política. 1886-1946, Vol. I. $1^{a}$ ed. Álvaro Tirado Mejía (dir. científico y académico), Jorge Orlando Melo y Jesús Antonio Bejarano (asesores). Bogotá: Planeta, 1989.

Biermann Stolle, Enrique. Distantes y distintos. Los emigrantes alemanes en Colombia, 1939-1945. Bogotá: Universidad Nacional de Colombia, División de Investigación Bogotá (DIB), Facultad de Ciencias Humanas, 2001.

Bushnell, David. Eduardo Santos y la política del buen vecino. Bogotá: El Áncora Editores, 1984.

Drekonja, Gerhard. Retos de la política exterior colombiana. Bogotá: Fondo editorial CEREC, 1983.

Galvis, Silvia y Donadío, Alberto. Colombia Nazi, 1939-1945: espionaje alemán, la cacería del FBI, Santos, López y los pactos secretos. Medellín: Hombre Nuevo Editores, 2002.

Henderson, James D. La modernización en Colombia. Los años de Laureano Gómez, 1889-1965. Medellín: Ed. Universidad de Antioquia, 2006.

Hobsbawm, Eric. Historia del siglo XX. Barcelona: Ed. Crítica, 2001.

Randall, Stephen J. Aliados y distantes. Historia de las relaciones entre Colombia y Estados Unidos desde la independencia hasta la guerra contra las drogas. Bogotá: Tercer Mundo Editores, 1992.

Santos, Enrique. La II Guerra Mundial vista por Calibán. Bogotá: Círculo de Lectores, 1988.

Thomson, David. Historia mundial de 1914 a 1968. México: Ed. Fondo de Cultura Económica, 2006.

Torres del Río, César. “Colombia y su política exterior. 1938-1948”. (Tesis de Maestría en Historia, Facultad de Ciencias Humanas, Universidad Nacional de Colombia, 1990).

Para citar este artículo: Mesa Valencia, Andrés Felipe. "El papel de Colombia en la Segunda Guerra Mundial. Desde el inicio de la conflagración hasta el ataque japonés a Pearl Harbor", Historia Caribe Vol. X No. 26 (Enero-Junio 2015): 291-319. DOI: http://dx.doi.org/10.15648/ hc. 26.2015 .10 